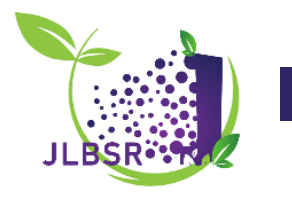

\title{
Optimization of Citric Acid Production by Aspergillus niger and Candida tropicalis for Solid State Fermentation Using Banana Peel Substrate
}

\author{
Ngozi Nma Odu ${ }^{1,}$, Gift Atumatuchukwu $\mathrm{Uzah}^{2}$, Nedie Patience Akani² \\ ${ }^{1}$ Department of Medical Laboratory Health Sciences, Faculty of Allied Health Sciences, PAMO University of Medical \\ Sciences, Port Harcourt, Rivers State Nigeria, (nodu@pums.edu.ng) \\ ${ }^{2}$ Department of Microbiology, Faculty of Science, Rivers State University, Nkpolu-Oroworukwo, Port Harcourt, Nigeria, \\ (gift.uzah@ust.edu.ng,nedieakani@gmail.com) \\ *Correspondence: nodu@pums.edu.ng
}

\begin{abstract}
Increasing cost of production and global demand for citric acid is driving research towards optimizing process conditions to yield very high quantity of the organic acid using abundant cheap substrates and selected microorganisms. Consequently, this study was designed to optimize the production of citric acid by making use of banana (Musa acuminata) peels (agro-waste) through means of solid state fermentation involving Aspergillus niger (Model A) and Candida tropicalis (Model B). In this study, a two-level, fivevariable full factorial design of response surface methodology (RSM) comprising 32 experimental runs for each model were used to develop a statistical model for the optimization of fermentation conditions which include: pH, glucose, zinc, ammonium chloride and methanol. The results obtained indicate that a second order polynomial model fitted adequately and statistically significant (p<0.0001) and $(p<0.0410)$ for Model $A$ and B, respectively. The optimum values of the variables were: $\mathbf{p H} 4$; glucose $5 \%$ w/v; zinc $2 \%$ w/v; ammonium chloride $0.5 \% \mathrm{w} / \mathrm{v}$; and methanol $3 \% \mathrm{v} / \mathrm{v}$. Under these conditions, the concentration of citric acid produced were $97.6 \mathrm{~g} / \mathrm{L}$ with a $\mathrm{pH}$ of 3.85 using Aspergillus niger and $113.6 \mathrm{~g} / \mathrm{L}$ with a $\mathrm{pH}$ of 3.45 using Candida tropicalis at $10 d a y s$ fermentation period. Experimental validation of the model indicated that no difference exist between the predicted and the actual yield results. Therefore, utilization of low-cost agro-waste banana peel which serve as suitable substrate for optimization of citric acid production is advocated because of their advantages such as income generation, reduction in environmental problems posed by food-waste disposal and public health hazards associated with it.
\end{abstract}

Keywords: Citric Acid, Banana Peel, Solid State Fermentation, Candida tropicalis, Optimization, Aspergillus niger

Received: July $10^{\text {th }}, 2020 /$ Accepted: September $04^{\text {th }}, 2020 /$ Online: September $12^{\text {th }}, 2020$

\section{INTRODUCTION}

Citric acid is scientifically known as 2-hydroxy-1, 2, 3propanetricarboxylic acid). Joint FAO/WHO Expert Committee on Food Additives have given approval for global recognition of citric acid as a generally regarded as safe (GRAS) organic acid considering its wide application in the pharmaceutical and food industries (Varshney, 2016; Dutta et al., 2019). It is a known weak acid which is also a biodegradable organic acid. Citric acid can also be described as a biochemical product usually obtained by fermentation (Oladele et al., 2015). Since global demand for citric acid has exceeded natural citric acid supply, the use of biotechnological fermentation processes has become imperative (Kishore and Reddy, 2011) Different substrates rich in carbon which is not limited to cassava bagasse, sucrose, brewery waste, carrot waste, cane molasses, beet molasses and glycerol have been utilized by researchers for the purpose of producing reasonable quantity of citric acid (Soccol et al., 2006). For 
commercial purposes, inexpensive substrates are selected for production of citric acid. Utilizing agro-industrial waste materials to be the source of carbon during the production process of citric acid is beneficial because it helps in managing waste as well as reduces the cost of production (Nadeem et al., 2010). Different types of fruits contain citric acid which gives fruit a sour taste (Khairan et al., 2019). In recent times, the use of fruit waste to produce citric acid is increasingly becoming more attractive to researchers because it is capable of reducing the cost of producing the organic acid (Varshney, 2016; Dutta et al., 2019) The use of banana and plantain peels fermented by Aspergillus niger to produce citric acid was successfully carried out by Khairan et al., 2019; Chukwuemeka et al. (2019).

Banana is a fruit daily consumed globally by every family which generates huge banana peels posing disposal problem in the environment (Kareem and Rahman, 2013). The increase in quantity of citric acid demanded globally makes it imperative to test alternative substrates for citric acid production. This calls for testing of banana peels rich in nutrients to ascertain its suitability as good substrate for the purpose of producing substantial quantity of citric acid.

For several decades, production of citric acid is commonly practiced by fermentation of different substrates by selected microorganisms such as bacteria, fungi and yeasts. For commercial purposes, Aspergillus niger as well as some yeasts like Saccharomyces species remains the microorganism of choice for production of citric acid (Oladele et al., 2015). In a recent study, Urak et al. (2014) reported the use of Yarrowia lipolytica for citric acid production. Also, Hesham et al. (2020) suggested the use of Candida tropicalis for commercial production of citric acid since it is more advantageous than $A$. niger which is a widely used fungus for that purpose. The advantages of using Candida tropicalis for citric acid production is due to its ability to utilize numerous substrates, reduced sensitivity to low concentrations of dissolved oxygen, associated with fewer health hazards, has ability to maintain stability against heavy metals, genetic variations and mechanical stress. Production of citric acid through fermentation is widely practiced because the operation is simple, control system involved is less sophisticated, energy requirement is low and importantly, frequent power failures do not have critical effect on the process (Kishore and Reddy, 2011). High production rate of citric acid leading to accumulation of this product is dependent on maintaining optimal level of sugar, acidity, dissolved oxygen, trace metals, nitrogen, phosphate, alcohol etc. (Jianlong et al., 1998). Several factors such as aeration (Darouneh et al., 2009; Angumeenal et al., 2013), carbon substrate source and concentration (Soccol et al., 2006), pH (del Campo et al., 2006), temperature, inoculum density (Auta et al., 2014), agitation (Benghazi et al., 2014), moisture content (Lingappa et al., 2001) etc. could affect the production of citric acid during fermentation.
Therefore, optimizing these variables is aimed at achieving best performance which will cause an upsurge of citric acid yield in large quantity.

The steps involved in using one-factor-at-a-time technique in order to optimize variables is time consuming. A strategy to get over it is by optimizing the effecting parameters using response surface methodology (RSM) which is a technique involved in empirical statistics which makes use of multiple regression analysis of quantitative data derived from experiments that are statistically designed by solving multivariate equations obtained simultaneously (Kumari et al., 2008; Adeoye et al., 2015).

Although banana peel has proven to be a substrate which can be used to produce citric acid, limited optimization studies have so far been carried out using different microbial species capable of synthesizing the organic acid. Therefore, this work was aimed at using RSM to optimize the conditions suitable for fermentation of banana peel by Candida tropicalis and Aspergillus niger in order to ascertain whether substantial quantity of citric acid could be produced or not.

\section{MATERIALS AND METHODS}

\section{A. The processing of substrate}

The substrate used in this work was banana (Musa acuminata) peels which was thoroughly washed using water obtained from tap water and rinsed using distilled water. The peels were chopped into smaller pieces and dried inside hot air oven at $40^{\circ} \mathrm{C}$ for $4 \mathrm{~h}$. The peels were further milled with a hand grinder to obtain fine particles and stored under aseptic conditions until they were used.

\section{B. The proximate composition of the substrate (banana peel)}

The proximate composition of the banana peel reported in wet weight basis (wb) was determined using the AOAC (1995) methods. The carbohydrate content was calculated using the difference method.

\section{Isolation, characterization and screening of fungal isolates}

Serial dilution was carried out using soil and fresh samples of agricultural products (cucumber and banana peels) by adopting the method used by Jalal et al. (2009). For the purpose of isolating Aspergillus niger and Candida tropicalis, $0.1 \mathrm{ml}$ solution was transferred from dilutions 10-4 and 10-5 and spread plated in triplicates on Potato Dextrose Agar (PDA) which was added with $10 \%$ lactic acid aimed at suppressing growth of bacteria. The inoculated culture plates were kept at $28 \pm 2{ }^{\circ} \mathrm{C}$ which lasted for 7 days. Selection of discreet colonies from the culture plates which were already incubated was dependent on their colonial morphologies. The selected colonies were purified by sub-culturing on freshly prepared PDA culture plates containing lactic acid using spread plate technique followed by incubation of the culture plates at $28 \pm 2{ }^{\circ} \mathrm{C}$ for a period of 7 days. Pure cultures obtained were subjected to characterization, identification and screening. Determination of various capabilities of citric acid positive fungal 
isolates was carried out using the method described by Patil and Patil (2014).

\section{Molecular characterization of screened isolates}

The procedure described by Uzah et al. (2020) was used in carrying out molecular characterization of the fungal isolates already screened for citric acid production. Molecular accession number (KT356204.1) and (EU440768.1) were assigned to Candida tropicalis and Aspergillus niger, respectively which were the fungal isolates successfully screened for citric acid production.

\section{E. Inoculum preparation}

Inoculum was prepared using the method adopted by Pandey (1992). The inoculum consists of spores from a 4-6 day old slant cultures. Preparation of suspension for the two isolates used in the study involved adding $10 \mathrm{ml}$ of sterile water which already contain 2 drops of $0.1 \%$ tween 80 added to the surface of the slant having copious spore growth. With a sterile inoculating needle, the spores in clumps was carefully scraped under aseptic conditions and the tubes were vigorously shaken to obtain a homogenous mixture of the suspension.

\section{F. Determination of inoculum size}

The spore density was measured using Nuebauer counting chamber following the procedure described by Blessing et al. (2018). Using the formula stated in equation 1 below, the number of spores was calculated.

$$
\text { Cell (spore } \left.\mathrm{ml}^{-1}\right)=\frac{N \times D F X 10^{6}}{A X D}--------(\text { Equation } 1)
$$

Represented with letter $A$ is the area counted $=5 \times 1 \mathrm{~m}^{2}$; Represented with letter $\mathrm{D}$ is depth of the counting chamber $=0.1$ $\mathrm{mm}$; Represented with letter $\mathrm{N}$ is the number of cells counted; DF represents the dilution factor.

\section{G. Experimental design for optimization of citric acid}

\section{production}

Optimization of citric acid production was achieved using response surface methodology (RSM) and full factorial design as adopted by Adeoye et al. (2015). A total of thirty two (32) experimental runs for each fungal isolate (Aspergillus niger and Candida tropicalis) with varied input values (two levels and five factors) were generated and carried out for optimization model development. The $2^{5}$ full factorial design was deployed while investigating the interaction effect of input parameters which the experimental model indicated had optimum citric acid yield are dependent on the following factors - pH (A), Carbon (B), Trace element (C), Nitrogen (D) and Methanol (E). The five factors or parameters used for the optimization were $\mathrm{pH}$, carbon source (glucose), nitrogen source (ammonium chloride), trace element (Zinc), and methanol. Although, addition of glucose as a carbon source has a minimal cost implication, the benefit which was aimed at enhancing microbial growth and citric acid synthesis is important because the substrate (banana peel) contains polysaccharide instead of simple sugar. The benefits of adding glucose to the medium is expected to outweigh the cost implication. Fermentation was carried out in a sucrose medium $(\mathrm{g} / \mathrm{L})$ which comprise sucrose $(150 \mathrm{~g}), \mathrm{KH}_{2} \mathrm{PO}_{4}(2.5 \mathrm{~g})$, $\mathrm{MgSO}_{4} .7 \mathrm{H}_{2} \mathrm{O}(0.23 \mathrm{~g})$ and $\mathrm{NH}_{4} \mathrm{NO}_{3}(3.0 \mathrm{~g})$. Based on the experimental design, $\mathrm{pH}$ of the media was adjusted by adding
HCL / NaOH. Fifty gram (50 g) of milled Musa accuminata peel was poured inside each of the $250 \mathrm{ml}$ capacity Erlenmeyer flask and moistened with $25 \mathrm{ml}$ of the fermentation medium, autoclaved at $121{ }^{\circ} \mathrm{C}$ at $15 \mathrm{psi}$ for $15 \mathrm{~min}$. Thereafter, the content of the flask was removed from the autoclave for cooling to take place until room temperature $\left(28 \pm 2{ }^{\circ} \mathrm{C}\right)$ was achieved before $10 \mathrm{ml}$ of the inoculum suspension was inoculated into the flasks and incubated at $28 \pm 2{ }^{\circ} \mathrm{C}$ for 12 days.

\section{H. Extraction of citric acid}

At $48 \mathrm{~h}$ interval of incubation, the citric acid content was extracted. After fermentation, $100 \mathrm{ml}$ of sterile distilled water was poured inside each of the flask in order to obtain slurry. Using a glass rod the content of each flask was stirred for $1 \mathrm{~h}$ and the slurry filtered using Whatman TM Qualitative filter paper No. 1 to separate the sediment. Further centrifugation of the filtrate was carried out at $10000 \mathrm{rpm}$ for 10 minutes. The clear filtrate from each flask was then used to estimate citric acid and $\mathrm{pH}$ (Pandey, 1992; Usami et al., 1998; Soccol et al., 2006).

\section{Estimation of citric acid}

Determination of the concentration of citric acid present in the culture filtrate was carried out by means of titration. Ten millilitre $(10 \mathrm{ml})$ culture broth was withdrawn and 3 drops of phenolphthalein was added as an indicator (Imandi et al., 2007; Khosravi and Zoghi, 2008). Exactly 0.1M NaOH was titrated against $10 \mathrm{ml}$ (equivalent to $10 \mathrm{~g}$ ) culture broth until the end-point was reached when the change in colour was noted. The quantity of $\mathrm{NaOH}$ used was read off as titre and the value was recorded. The formula which was adopted by AOAC (1995) was used to calculate the citric acid $(\%)$ released.

$\%$ Citric acid $=$

$\underline{\text { Normality } \times \text { Volume of } \mathrm{NaOH} \times \text { Equiv. wt. of } \mathrm{CA} \times \text { Dilution factor }}$ ---- (Equation 2) Weight of Sample (g) X $10 \mathrm{ml}$

\section{J. Statistical analysis}

DESIGN EXPERT version 11 enabled the use of Response Surface Methodology (RSM) as well as Full Factorial Design for the purpose of developing optimization model for citric acid production. The parameters were done in triplicates and results obtained were analyzed using oneway analysis of variance (one-way ANOVA) as well as multiple range tests in order to determine the differences in the means at $5 \%(0.05)$ significant level.

\section{RESULTS}

The details of morphological characterization of the fungal isolates used in this study is presented in a recently published report by Uzah et al. (2020) which forms part of this publication. Figure $1 \mathrm{~A}$ and $\mathrm{B}$ are the colonial morphology of Aspergillus niger and Candida tropicalis which were screened for their ability to produce citric acid. Figure 1, C and D shows Aspergillus niger and Candida tropicalis, respectively with a yellow zone around their colonies which is an indication that the isolates produced organic acid. 

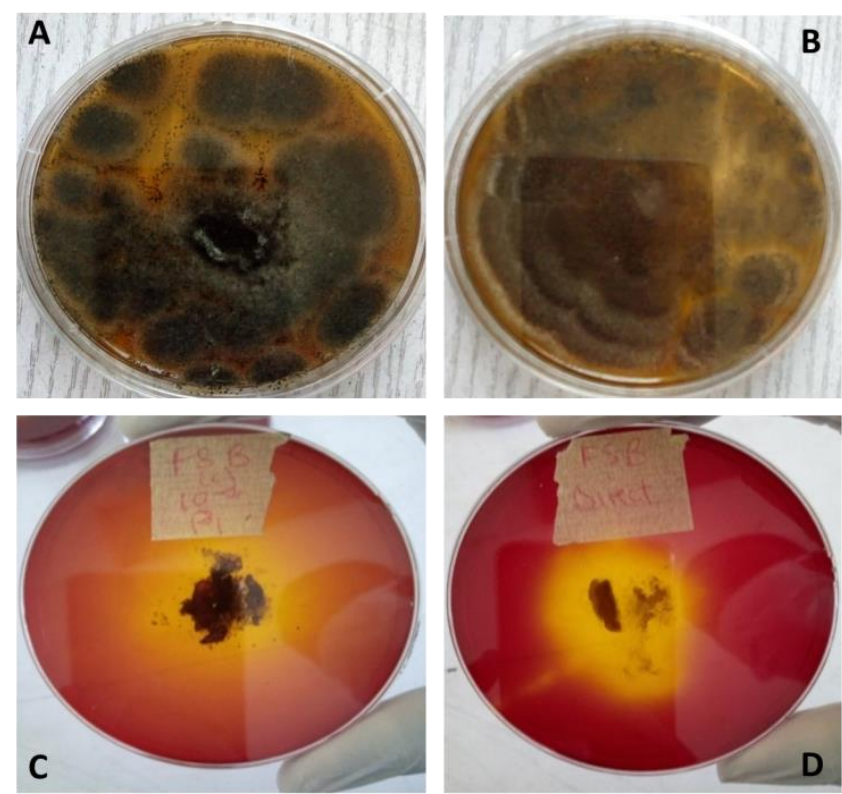

Figure 1. Colonial morphology of Aspergillus niger and Candida tropicalis. A: Colonial morphology of Aspergillus niger on Potato dextrose agar. B: Colonial morphology of Candida tropicalis on Potato dextrose agar. C: Culture plate showing organic acid production with yellow zones around colonies of Aspergillus niger. D: Culture plate showing organic acid production with yellow zone around colonies colonies of Candida tropicalis.

The proximate composition of the banana peel is presented in Figure 2. The moisture, ash, protein, fat, crude fiber and carbohydrate content is $86.28 \%, 1.76 \%, 0.60 \%, 1.15 \%$, $4.67 \%$ and $5.55 \%$, respectively. The nitrogen content of the banana peel is $0.10 \pm 0.007 \%$.

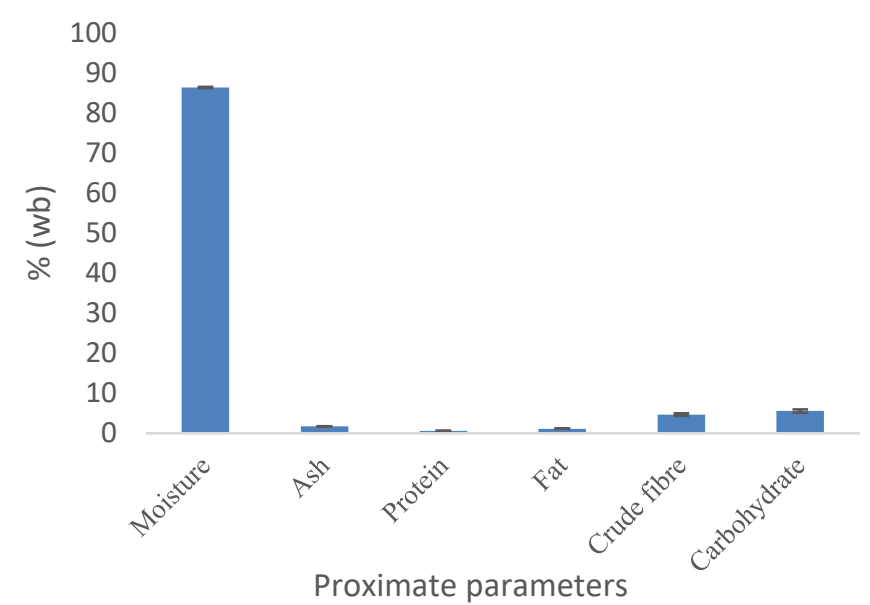

Figure 2. Proximate composition of banana peel; Key: $\mathrm{Wb}$ - Weight wet basis
The result of the response from optimized production of citric acid depicted in Table 1 indicates that optimization A setup (Aspergillus niger) had the highest mean value of $47.2 \mathrm{~g} / \mathrm{L}$ on runoder 16 and least mean value of $12.96 \mathrm{~g} / \mathrm{L}$ on runorder 11 while optimization $\mathrm{B}$ setup (Candida tropicalis) had the highest mean value of $37.6 \mathrm{~g} / \mathrm{L}$ on runorder 22 and least mean value of $9.76 \mathrm{~g} / \mathrm{L}$ on runorder 32.

The quadratic model analysis of variance (ANOVA) using Aspergillus niger and Candida tropicalis are shown in Table 2 and 4, respectively. This is an indicator that model F-value of 6.86 and $p<0.05$ suggests that the model terms were significant. With respect to this study, 'B', 'AE', 'ADE' and 'ABCD' are model terms which are significant. Also, Lack of Fit F-value 0.59 suggests that Lack of Fit is not significantly relative to the pure error. This indicates that model F-value 4.36 and $p<0.05$ suggests that the model terms are significant. In this situation, ' $\mathrm{CE}$ ' is a significant model term. Also, the Lack of Fit F-value 1.14 suggests that Lack of Fit is not significant relative to the pure error.

The coefficient estimate of the fitted model denotes the predictable change which occurred in response per unit change in factor value in a situation all the factors remaining are kept constant are shown in Table 3 and 5. Using Aspergillus niger for the process optimization model, Table 2 shows an intercept coefficient of 27.30 with VIF of 1.0 while Candida tropicalis (Table 4) shows an intercept coefficient of 25.58 and VIF of 1.0.

Surface graph using contour plots (Figures 3-5) shows the variations and interaction effects between two input parameters on response. In process optimization model (Aspergillus niger), Fig. 3 shows the interaction between $\mathrm{pH}$ and methanol which indicates that the citric acid yield was at its peak of $28 \mathrm{~g} / \mathrm{L}$ when $\mathrm{pH}$ is at 5.5 and methanol $2.6 \%$. Figure 4 shows no interaction between $\mathrm{pH}$ and nitrogen. In process optimization model (Candida tropicalis), Figure 5 shows the interaction between methanol and trace element which indicates that the citric acid yield was at its peak of $26 \mathrm{~g} / \mathrm{L}$ when methanol is at 2.4 $\%$ and trace element $1.4 \%$.

In Figures 3 and 4, the response surface plots can be seen as being nearly plane whereas the contour displayed a nearly parallel straight lines which can be attributed to statistically low interaction coefficients.

Also considering the contrary twists in all response, the surface graphs could easily be observed especially with interaction terms having higher coefficient in mathematical model. 
Table 1. Full factorial design procedure and response towards the yield of citric acid

\begin{tabular}{|c|c|c|c|c|c|c|c|c|c|c|c|c|}
\hline \multirow[b]{2}{*}{ Runorder } & \multicolumn{5}{|c|}{ Different coded factors } & \multicolumn{5}{|c|}{ The actual factors } & \multicolumn{2}{|c|}{ Response (g/L) } \\
\hline & A & B & $\mathrm{C}$ & $\mathrm{D}$ & $\mathrm{E}$ & $\mathrm{pH}$ & $\begin{array}{c}\text { Carbon } \\
\text { (Glucose) } \\
\% \mathrm{w} / \mathrm{v}\end{array}$ & $\begin{array}{c}\text { Trace element } \\
\text { (Zinc) } \\
\% \mathrm{w} / \mathrm{v}\end{array}$ & $\begin{array}{c}\text { Nitrogen } \\
\text { (Ammonium } \\
\text { chloride) } \\
\% \mathrm{w} / \mathrm{v}\end{array}$ & $\begin{array}{l}\text { Methanol } \\
\% \mathrm{v} / \mathrm{v}\end{array}$ & $\begin{array}{c}\text { Optimization A } \\
\text { (Aspergillus niger) }\end{array}$ & $\begin{array}{c}\text { Optimization B } \\
\text { (Candida } \\
\text { tropicalis) }\end{array}$ \\
\hline 1. & 1 & 1 & 1 & 1 & 1 & 6 & 5 & 1 & 0.25 & 2 & 30.72 & 33.6 \\
\hline 2. & 1 & 1 & 1 & 1 & 2 & 6 & 5 & 1 & 0.25 & 3 & 28 & 36.8 \\
\hline 3. & 1 & 1 & 1 & 2 & 1 & 6 & 5 & 1 & 0.5 & 2 & 20.16 & 31.36 \\
\hline 4. & 1 & 1 & 1 & 2 & 2 & 6 & 5 & 1 & 0.5 & 3 & 27.2 & 24.825 \\
\hline 5. & 1 & 1 & 2 & 1 & 1 & 6 & 5 & 2 & 0.25 & 2 & 20 & 26.88 \\
\hline 6. & 1 & 1 & 2 & 1 & 2 & 6 & 5 & 2 & 0.25 & 3 & 23.2 & 27.04 \\
\hline 7. & 1 & 1 & 2 & 2 & 1 & 6 & 5 & 2 & 0.5 & 2 & 14.4 & 13.76 \\
\hline 8. & 1 & 1 & 2 & 2 & 2 & 6 & 5 & 2 & 0.5 & 3 & 20 & 21.92 \\
\hline 9. & 1 & 2 & 1 & 1 & 1 & 6 & 10 & 1 & 0.25 & 2 & 13.6 & 30.08 \\
\hline 10. & 1 & 2 & 1 & 1 & 2 & 6 & 10 & 1 & 0.25 & 3 & 23.84 & 33.6 \\
\hline 11. & 1 & 2 & 1 & 2 & 1 & 6 & 10 & 1 & 0.5 & 2 & 12.96 & 31.68 \\
\hline 12. & 1 & 2 & 1 & 2 & 2 & 6 & 10 & 1 & 0.5 & 3 & 31.2 & 30.88 \\
\hline 13. & 1 & 2 & 2 & 1 & 1 & 6 & 10 & 2 & 0.25 & 2 & 26.4 & 24.96 \\
\hline 14. & 1 & 2 & 2 & 1 & 2 & 6 & 10 & 2 & 0.25 & 3 & 33.92 & 29.12 \\
\hline 15. & 1 & 2 & 2 & 2 & 1 & 6 & 10 & 2 & 0.5 & 2 & 22.72 & 29.92 \\
\hline 16. & 1 & 2 & 2 & 2 & 2 & 6 & 10 & 2 & 0.5 & 3 & 47.2 & 28.8 \\
\hline 17. & 2 & 1 & 1 & 1 & 1 & 4 & 5 & 1 & 0.25 & 2 & 40.8 & 28.8 \\
\hline 18. & 2 & 1 & 1 & 1 & 2 & 4 & 5 & 1 & 0.25 & 3 & 19.04 & 18.72 \\
\hline 19. & 2 & 1 & 1 & 2 & 1 & 4 & 5 & 1 & 0.5 & 2 & 25.92 & 28.64 \\
\hline 20. & 2 & 1 & 1 & 2 & 2 & 4 & 5 & 1 & 0.5 & 3 & 46.08 & 31.2 \\
\hline 21. & 2 & 1 & 2 & 1 & 1 & 4 & 5 & 2 & 0.25 & 2 & 27.2 & 28.16 \\
\hline 22. & 2 & 1 & 2 & 1 & 2 & 4 & 5 & 2 & 0.25 & 3 & 27.2 & 37.6 \\
\hline 23. & 2 & 1 & 2 & 2 & 1 & 4 & 5 & 2 & 0.5 & 2 & 29.12 & 27.36 \\
\hline 24. & 2 & 1 & 2 & 2 & 2 & 4 & 5 & 2 & 0.5 & 3 & 20 & 30.4 \\
\hline 25. & 2 & 2 & 1 & 1 & 1 & 4 & 10 & 1 & 0.25 & 2 & 30.88 & 19.04 \\
\hline 26. & 2 & 2 & 1 & 1 & 2 & 4 & 10 & 1 & 0.25 & 3 & 22.4 & 12.32 \\
\hline 27. & 2 & 2 & 1 & 2 & 1 & 4 & 10 & 1 & 0.5 & 2 & 38.88 & 28.64 \\
\hline 28. & 2 & 2 & 1 & 2 & 2 & 4 & 10 & 1 & 0.5 & 3 & 24.8 & 14.88 \\
\hline 29. & 2 & 2 & 2 & 1 & 1 & 4 & 10 & 2 & 0.25 & 2 & 44.32 & 12.8 \\
\hline 30. & 2 & 2 & 2 & 1 & 2 & 4 & 10 & 2 & 0.25 & 3 & 39.84 & 21.92 \\
\hline 31. & 2 & 2 & 2 & 2 & 1 & 4 & 10 & 2 & 0.5 & 2 & 28 & 13.12 \\
\hline 32. & 2 & 2 & 2 & 2 & 2 & 4 & 10 & 2 & 0.5 & 3 & 13.6 & 9.76 \\
\hline
\end{tabular}

Table 2. Analysis of variance (partial sum of squares) for optimization setup A (Aspergillus niger) using Response surface quadratic model

\begin{tabular}{|c|c|c|c|c|c|c|}
\hline Source & Sum of Squares & df & Mean Square & F-value & p-value & Level of Significance \\
\hline Model & 1732.97 & 4 & 433.24 & 6.86 & 0.0001 & Significant \\
\hline B-Carbon & 459.67 & 1 & 459.67 & 7.28 & 0.0091 & \\
\hline AE & 416.16 & 1 & 416.16 & 6.59 & 0.0128 & \\
\hline ADE & 494.62 & 1 & 494.62 & 7.83 & 0.0069 & \\
\hline ABCD & 362.52 & 1 & 362.52 & 5.74 & 0.0198 & \\
\hline Residual & 3725.54 & 59 & 63.14 & & & \\
\hline Lack of Fit & 1241.00 & 27 & 45.96 & 0.5920 & 0.9159 & Is not significant \\
\hline Pure Error & 2484.53 & 32 & 77.64 & & & \\
\hline Cor Total & 5458.51 & 63 & & & & \\
\hline
\end{tabular}

With respect to the $3 \mathrm{D}$ graph of combination effect, our results revealed that $\mathrm{pH}$ played the most significant effect in achieving citric acid yield compared with other input parameters.

Table 3. Estimated coefficients which is for the fitted model considering the coded factors for optimization A (Aspergillus niger)

\begin{tabular}{|c|c|c|c|c|c|c|}
\hline Factor & Coefficient & $\mathrm{df}$ & Standard Error & $95 \%$ CI Low & 95\% CI High & VIF \\
\hline Intercept & 27.30 & 1 & 0.9933 & 25.31 & 29.29 & \\
\hline B-Carbon & -2.68 & 1 & 0.9933 & -4.67 & -0.6924 & 1.0000 \\
\hline $\mathrm{AE}$ & -2.55 & 1 & 0.9933 & -4.54 & -0.5624 & 1.0000 \\
\hline $\mathrm{ADE}$ & -2.78 & 1 & 0.9933 & -4.77 & -0.7924 & 1.0000 \\
\hline $\mathrm{ABCD}$ & -2.38 & 1 & 0.9933 & -4.37 & -0.3924 & 1.0000 \\
\hline
\end{tabular}


Table 4. Analysis of variance (partial sum of squares) for optimization setup B (Candida tropicalis) using Response surface quadratic model

\begin{tabular}{ccccccc}
\hline Source & Sum of Squares & $\mathrm{df}$ & Mean Square & F-value & p-value & Level of Significance \\
\hline Model & 236.04 & 1 & 236.04 & 4.36 & 0.0410 & significant \\
CE & 236.04 & 1 & 236.04 & 4.36 & 0.0410 & Is not significant \\
Residual & 3358.31 & 62 & 54.17 & & \multirow{2}{*}{0.3558} & \\
Lack of Fit & 1736.19 & 30 & 57.87 & & & \\
Pure Error & 1622.12 & 32 & 50.69 & & & \\
Cor Total & 3594.35 & 63 & & & \\
\hline
\end{tabular}

Table 5. Estimated coefficients which is for the fitted model considering the coded factors for optimization B (Candida tropicalis)

\begin{tabular}{ccccccc}
\hline Factor & Coefficient & df & Standard Error & $95 \%$ CI Low & 95\% CI High \\
\hline Intercept & 25.58 & 1 & 0.9200 & 23.74 & 27.42 & VIF \\
CE & 1.92 & 1 & 0.9200 & 0.0815 & 3.76 & 1.0000 \\
\hline
\end{tabular}

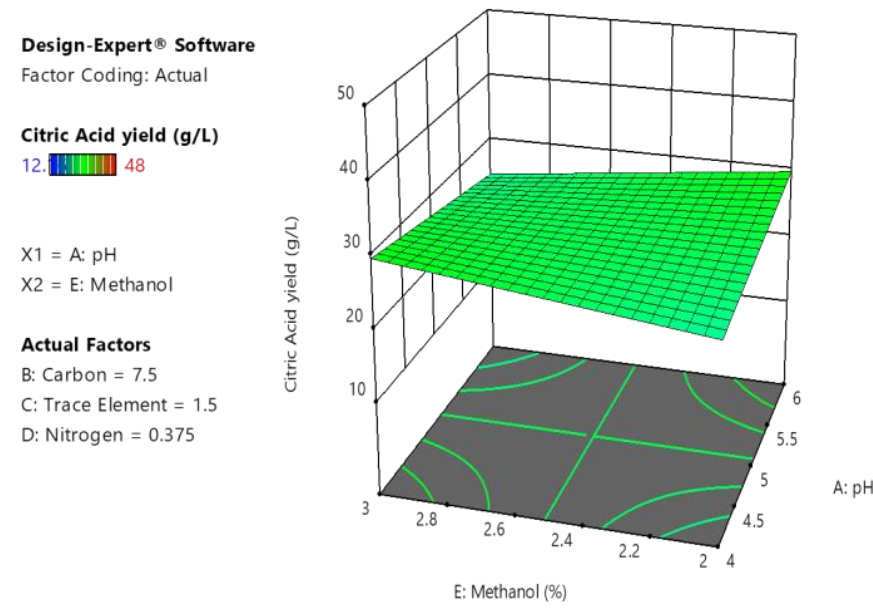

Figure 3. Response surface graph for the model optimization (Aspergillus niger) showing the interaction between methanol and $\mathrm{pH}$ for the production of citric acid.
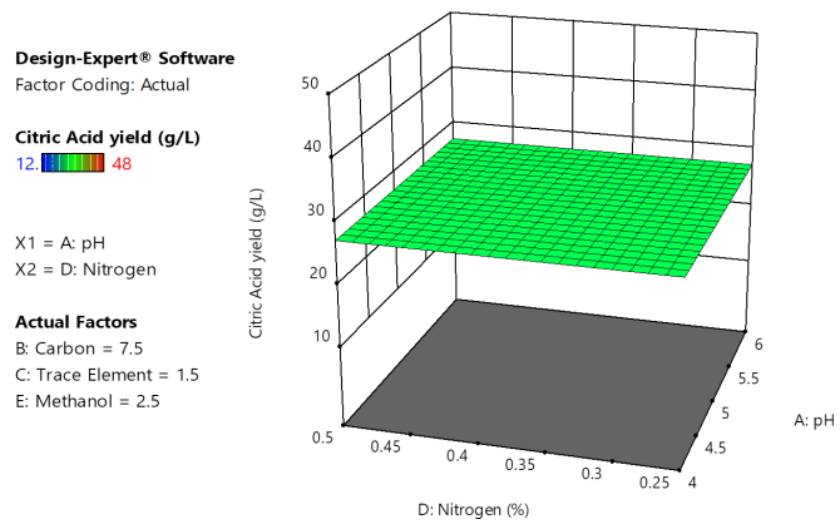

Figure 4. Response surface graph for the model optimization (Aspergillus niger) showing the interaction between nitrogen and $\mathrm{pH}$ for the production of citric acid

Final production of citric acid from the developed process optimization models are depicted in Fig. 6-7. The line plot which describes production of citric acid in relation to $\mathrm{pH}$ and time shown in Fig. 6 indicates that the highest yield of citric acid of $97.6 \mathrm{~g} / \mathrm{L}$ at day 10 with final $\mathrm{pH}$ of 3.85 using Aspergillus niger while Fig. 7 shows the line plot of citric acid production using Candida tropicalis which indicates that maximum possible yield of citric acid was $113.6 \mathrm{~g} / \mathrm{L}$ at day 10 with final $\mathrm{pH}$ of 3.45 . To estimate the quantity of citric acid released by Aspergillus niger, $10 \mathrm{ml}$ of citric acid which is equivalent to $10 \mathrm{~g}$ was neutralized by 19.64 $\mathrm{ml}$ of $\mathrm{NaOH}$. Similarly, estimation of citric acid released by Candida tropicalis involved $22.87 \mathrm{ml}$ of $\mathrm{NaOH}$ which neutralized $10 \mathrm{ml}$ of citric acid being equivalent to $10 \mathrm{~g}$.

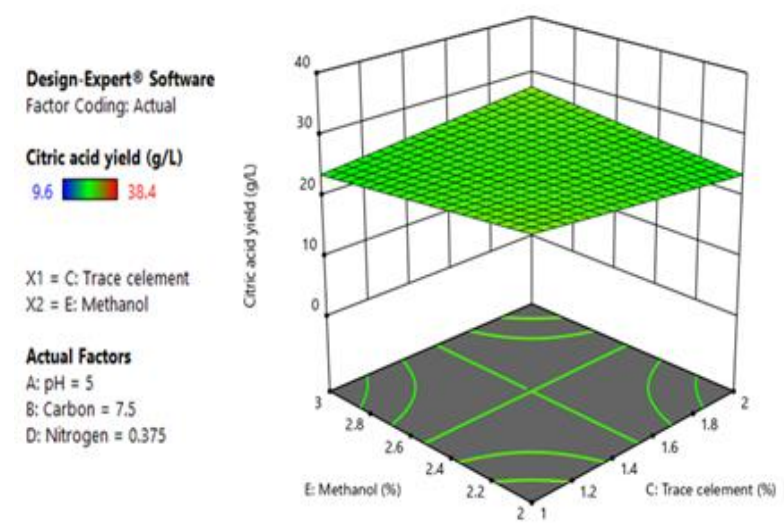

Figure 4. Response surface graph for the model optimization (Candida tropicalis) showing the interaction between methanol and trace element for the production of citric acid

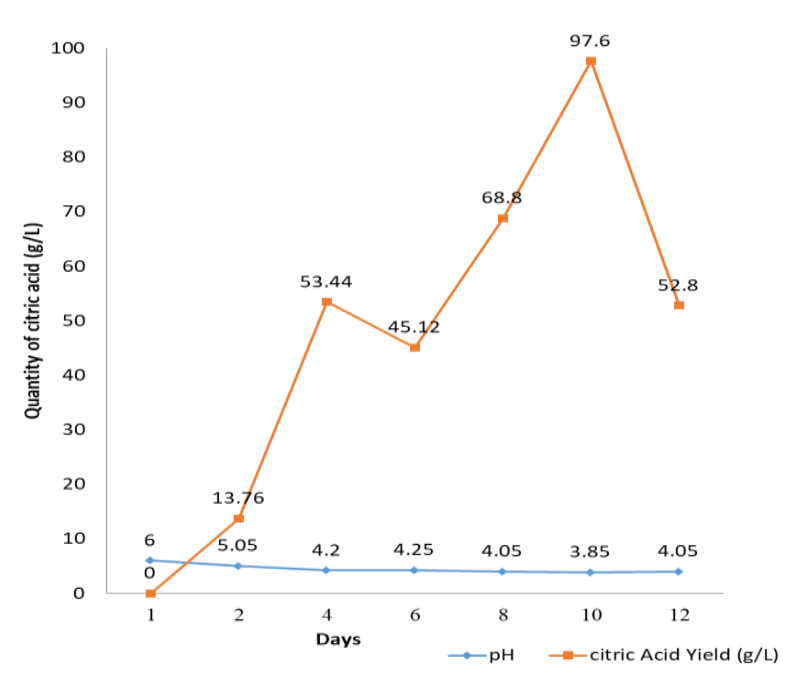

Figure 6. Line plot of citric acid production from process optimization model (Aspergillus niger) 


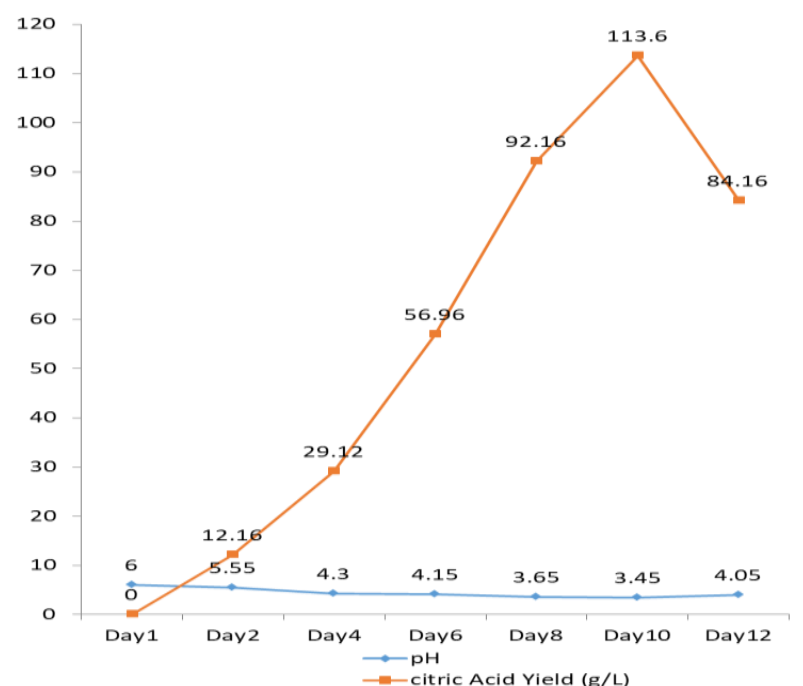

Figure 7. Line plot of citric acid production from process optimization model (Candida tropicalis)

\section{DISCUSSION}

\section{A. Proximate composition of banana peels}

According to Anhwange et al. (2009), moisture, ash, protein, crude lipid, carbohydrate, and crude fibre content of banana peel is $6.70,8.50,0.90,1.70,59$, and $31.70 \%$, respectively. This result partially agrees with the values obtained from this study. The time of harvesting, varieties of banana and cultural practices could be responsible for the variations in the proximate composition of the banana peel. Nitrogen constitute the basic part of cell proteins, capable of inducing the formation of pellets in filamentous fungi. Therefore, it plays a significant role in the production of citric acid. Furthermore, studies have demonstrated that the specific type of nitrogen source employed in citric acid production usually influences the yield of citric acid Kudzai et al. (2016). The carbohydrate content $(5.55 \%)$ of the banana peels which serves as the carbon source was low. This forms part of the reason glucose was added to the fermentation medium to enhance yield of the citric acid. Similarly, ammonium chloride was also added as a nitrogen source since the nitrogen content of the banana peel was $0.10 \%$.

\section{B. Model development for process optimization}

The traditional 'one-factor at a time' technique usually adopted to optimize a multivariable system is challenging because precious time is wasted in the process. Apart from that, the technique fail to capture the interactions that come into play between the variables (Abonama et al., 2014). It is evident that this method involves carrying out a large number of experiments before the optimum levels can be determined. The setback occasioned by single factor optimization process can be triumphed by optimizing all the affecting factors using full factorial or central composite design (Box and Wilson, 1951), of response surface methodology (RSM).

Response surface methodology (RSM) which involves 2 levels and 5 factors was used to develop quadratic model for process optimization which involves fermentation of citric acid by Aspergillus niger and Candida tropicalis making use of banana peels as a substrate. Findings from our study shows that increase in citric acid yield occurred while fermentation lasted. Low P-value (0.001) and high F-value (6.86) for Aspergillus niger as well as low Pvalue (0.0410) and high F-value (4.36) for Candida tropicalis further substantiate statistical significance and non-significant lack of fit for both microbial genera is good and makes the model to fit. This observation agrees with the findings reported by Adeoye et al. (2015), which stated that the greater the F-value from a unit, the more certain it is that the factors explain adequately the variation in the data about its means and effect of estimated factors are real. Based on results obtained from RSM applied in this study, adequate precision signal to noise ratio was 9.356 for Aspergillus niger and 2.9522 for Candida tropicalis gives an indication that adequate signal for the model will be used to navigate the design space.

Result obtained from this study shows an intercept coefficient of 27.30 with Variance Inflation Factor (VIF) of 1.0 using Aspergillus niger while Candida tropicalis shows an intercept coefficient of 25.58 and VIF of 1.0. Thus, the intercept in an orthogonal design depicts the overall average response which involves all the runs. The coefficients describe the adjustments around the average considering the factor settings. Situations whereby the factors are orthogonal, the VIFs are 1; VIFs $>1$. This suggests its multi-collinearity. Therefore, each time the VIF becomes higher, the correlation of factors becomes more severe. Based on existing rough rule, VIFs $<10$ are tolerable (Hair et al., 1995, Ringle et al., 2015).

\section{Input parameters interaction and their effects on production of citric acid}

This study has shown that $\mathrm{pH}$, carbon, trace element, nitrogen and methanol influenced the experimental citric acid yields whereas incubation period and temperature remain the constant variables. The high yield is attributable to the fermenting organisms, substrate and nutritional contents of fermentation medium (Kubicek, 1998; Kobomoje et al., 2013). Large variations in citric acid yields 12.96 - $47.2 \mathrm{~g} / \mathrm{L}$ by Aspergillus niger and 9.76 -37.6 $\mathrm{g} / \mathrm{L}$ by Candida tropicalis shown in Table 1 demonstrate that the bioprocess was highly susceptible to the input parameters considered in this study. Our results revealed that increase in carbon and other input parameters above the optimum point reduced citric acid yields. In the first model which involved Aspergillus niger, $\mathrm{pH}$ was identified as a factor which had the most effect on citric acid production followed by methanol. Meanwhile, trace 
element was found to be most effective in the second model that involved Candida tropicalis.

Surface results gives an indication that input parameters becoming higher will directly lower the citric acid yields. These results showed consistency with the coefficient in the statistical model. 3D modelling result obtained as well as their contours clearly shows the direction sensitive towards citric acid yield. Thus, observation of curved contour lines could be attributed to high interaction effects (Bingol et al., 2010). Fig. 3-5 shows that if input parameters namely $\mathrm{pH}$, carbon, trace element, nitrogen and methanol were maintained at $5.5,5 \%, 2 \%, 0.25 \%$ and $2 \%$ respectively, what would happen will be a consequential increase in yield of citric acid. This result is in agreement with findings reported by Akdeniz et al. (2012). However, further increase in these input parameters will not greatly impact on production of citric acid (Adeoye et al., 2015). Therefore, these observations with the various input parameters are essentially significant in the course of production of citric acid in a large scale. In addition, $2 \%$ optimum methanol concentration obtained from this study indicates the impact of low molecular weight alcohol (methanol) in citric acid production which is in agreement with the investigations of some researchers ( $\mathrm{Yu}$ et al., 2017, Assadi and Nikkhah, 2002), who reported a remarkable increase in citric acid yield with $2-3 \%$ methanol. Furthermore, the addition of 3-4 \% (v/v) methanol to the fermentation medium could retard the fungal growth and sporulation, thereby improving the citric acid yield. Also, it is suggested that the presence of methanol may increase the permeability of the cell to citrate, and the cell responds to the diminished intracellular level by increasing production via repression of 2oxoglutarate dehydrogenase. Although the exact role of methanol in citric acid production is not clear, it is suggested that methanol serve as a source of acetyl CoA which might bring about increase in the transfer of nutrients across the cell membrane. Consequently, an upsurge in the excretion of citric acid is bound to occur (Kapoor et al., 1982; Jianlong, 1998; Navaratnam et al., 1998).

\section{Citric acid Production from the optimization model}

Validation of experimental design of the optimized profile as shown in Fig. 6 and 7 made it known that maximum yield of citric acid (97.6 g/L) was achieved using Aspergillus niger and $113.6 \mathrm{~g} / \mathrm{L}$ using Candida tropicalis in the laboratory with improvement of $36-70 \mathrm{~g} / \mathrm{L}$ over the optimization response. The results obtained indicate that citric acid yield was higher as to compare with research findings of Kareem and Rahman (2013) which reported that maximum yield of citric acid $82.12 \mathrm{~g} / \mathrm{Kg}$ was obtained using banana peel, $1 \%$ methanol and trace element (10 ppm) at $30{ }^{\circ} \mathrm{C}$.

It has been established that fermentation time is very important in substrate utilization. Therefore, it influences the yield of citric acid. Fig. 6 and 7 shows that maximum citric acid yield $97.6 \mathrm{~g} / \mathrm{L}$ and $113.6 \mathrm{~g} / \mathrm{L}$ was obtained after fermentation lasted for 10 days at $28 \pm 2{ }^{\circ} \mathrm{C}$ using Aspergillus niger and Candida tropicalis, respectively. This observation corroborates the findings of Varsha (2015) and Khairan et al., (2019) who reported that high yield of citric acid occurred after fermentation lasted for 10 days $(240 \mathrm{~h})$. However, the result is not in agreement with Nadeem et al. (2010) and Blessing et al. (2018) which reported that highest citric acid yield occurred after $192 \mathrm{~h}$ fermentation. In another related study, Kareem and Rahman (2013) reported optimum yield of citric acid $(82.2 \mathrm{~g} / \mathrm{kg})$ after $92 \mathrm{~h}$ fermentation. The result obtained at Day 1 shows that production of citric acid did not occur. This could be due to prolonged lag phase which is in agreement with the findings of Blessing et al. (2018) and Varsha (2015).

Since wild fungal isolates were selected for citric acid production and vegetative cycle of the isolates takes 3-4 days to complete before sporulation could commence, this could have resulted in the extension of the fermentation period for optimum citric acid production up to 10 days. Hence, the need for genetic enhancement of the isolates for efficient performance. After 10 days fermentation at $28 \pm 2$ ${ }^{\mathrm{o}} \mathrm{C}$, the results obtained shows that citric acid yield increased progressively to an optimum point with reduction in $\mathrm{pH}$ from the initial value of 6.0 in the medium. Maximum yield of citric acid $97.6 \mathrm{~g} / \mathrm{L}$ at $\mathrm{pH}$ of 3.85 was obtained using Aspergillus niger and $113.6 \mathrm{~g} / \mathrm{L}$ at $\mathrm{pH}$ of 3.45 using Candida tropicalis after 10 days fermentation. Sawant et al. (2018) reported that solid substrate fermentation resulted in $82.12 \mathrm{~g} / \mathrm{L}$ yield of citric acid using banana peels and Aspergillus niger UABN 210. Higher yield of citric acid reported in this study compared with the quantity reported by Sawant et al. (2018) could be as a result of the optimization condition adopted and strain of the Aspergillus niger and Candida tropicalis used for the production process. Result from this study shows that $\mathrm{pH}$ of 3.45 was most suitable for citric acid production using banana peel as substrate and Candida tropicalis as the fermenting yeast. Abonama et al. (2014) and Afolabi et al. (2018) reported highest citric acid yield of $30 \mathrm{~g} / \mathrm{L}$ and 4.2 $\mathrm{g} / \mathrm{L}$, respectively using Candida tropicalis under submerged fermentation. Hence, the result obtained for this study further substantiate the fact that Candida tropicalis performs best under solid state fermentation than submerged fermentation. According to Kareem and Rahman (2013), during the early stages of fermentation, it is important to maintain $\mathrm{pH}$ for a specific amount of biomass to be formed. This condition is very important to achieve maximum yield, growth and metabolic activities of the microorganisms. In our study, consistent decrease in $\mathrm{pH}$ was observed as fermentation time increased.

This could be attributed to citric acid formation and accumulation. When ammonia was absorbed by the germinating spores, it is probable that protons were released. This condition might have resulted in the release 
of hydrogen ions which resulted in lowering $\mathrm{pH}$ of the medium (Max et al., 2010). Notably, our findings corroborates with earlier studies by Thiruvengadam and Thangavel (2016) which observed that maximum citric acid yield occurred when the initial $\mathrm{pH}$ was 6.0. The result obtained from this study is close to that which was reported by Khosravi and Zoghi (2008) and Blessing et al. (2018) which reported that yield of citric acid was at its maximum when initial $\mathrm{pH}$ was 5.5. Thus, fungal strains is suggested to thrive best in acidic medium which is within $\mathrm{pH}$ range of 3.0-6.0 (Fawole and Odunfa, 2003) A pH that range from 2.0-6.0 is frequently maintained for solid state and submerged fermentation (Adham, 2002). Thus, these conditions have great impact on citric acid production (Ajala et al., 2020).

Since this study was able to demonstrate that banana peel which is a cheap and readily available agricultural waste could serve as a substrate to produce citric acid, it is expected that after carrying out detailed cost analysis based on the conditions suitable for the process which is recommended from this study, the production cost will be low and highly competitive with conventional methods.

\section{V.CONCLUSION}

The $2^{5}$ full factorial design deployed in this study to investigate the effect resulting from interaction of input parameters as well as the experimental model indicated that optimum citric acid yield was dependent on various factors namely $\mathrm{pH}$, carbon, trace element, nitrogen and methanol. The maximum optimization responses for both models were $47.2 \mathrm{~g} / \mathrm{L}$ at runorder (16) using Aspergillus niger and 37.6 $\mathrm{g} / \mathrm{L}$ at runorder (22) using Candida tropicalis. Results obtained showed that all the five factors impacted greatly on citric acid yield. The main effects were found to be in coded form (ADE, B, AE, and $\mathrm{ABCD}$ ) using Aspergillus niger and (CE) using Candida tropicalis. The effects of experimental variability and their interactions on the response (citric acid) indicate that increase in carbon and other input parameters above it optimum point reduced citric acid yields. The most effective factor was $\mathrm{pH}$ followed by methanol and trace element in first and second model, respectively. Therefore, the experimental validation of the process optimization brought about maximum yield of 97.6 $\mathrm{g} / \mathrm{L}$ citric acid using Aspergillus niger and $113.6 \mathrm{~g} / \mathrm{L}$ using Candida tropicalis within the period of 10days fermentation. This study has successfully projected the prospects of using banana peels which ordinarily constitute an environmental challenge in terms of waste disposal to create wealth through production of citric acid.

\section{REFERENCES}

Abonama, O.M., Hoda-Mahrous, E.B.A. F., Hamza, H.A. (2014). Production of citric acid by Candida tropicalis under fermentation conditions using a plackett-burman design. Journal of Life Sciences Research, 1(3), 70-75.

Adeoye, A.O., Lateef, A., Gueguim-Kana, E.B. (2015). Optimization of citric acid production using a mutant strain of Aspergillus niger on cassava peel substrate. Biocatalysis and Agricultural Biotechnology, $4,568-574$.

Adham, N.Z. (2002). Attempts at improving citric acid fermentation by Aspergillus niger in beet-molasses medium. Bioresource Technology, 84(1), 97-100.

Afolabi, F.T., Adeyemo, S.M., Balogun, H.O. (2018). Fermentation conditions and process optimization of citric acid production by yeasts. The International Journal of Biotechnology, 7(1), 51-63.

Ajala, A.S., Adeoye, A.O., Olaniyan, S.A. \& Fasonyin, O.T. (2020). A study on effect of fermentation conditions on citric acid production from cassava peels. Scientific African, 8, 1-6.

Akdeniz, B., Dilek, D.K., Neriman, B. (2012). Use of factorial experimental design for analyzing the effect of storage conditions on color quality of sun-dried tomatoes. Scientific Research and Essays, $7(4), 477-489$.

Angumeenal, A.R., Venkappayya, D. (2013). An overview of citric acid production. LWT-Food Science and Technology, 50(2), 367-370.

Anhwange, B.A., Ugye, T.J., Nyiaatagher, T.D. (2009). Chemical composition of Musa sapientum (banana) peels. Electronic Journal of Environmental, Agricultural and Food Chemistry, 8(6), 437-442.

AOAC (1995). Official Methods of Analysis, $16^{\text {th }}$ Ed. Association of Official Analytical Chemist, Washington D.C.

Auta, H.S., Abidoye, K.T., Tahir, H., Ibrahim, A.D., Aransiola, A.S. (2014). Citric acid production by Aspergillus niger cultivated on Parkia biglobosa fruit pulp. International Scholarly Research Notices, 1-8.

Assadi, M.M., Nikkhah, M. (2002). Production of Citric Acid from Date Pulp By Solid State Fermentation. Journal of Agricultural Science and Technology, 4: 119-125

Benghazi, L., Record, E., Suárez, A., Gomez-Vidal, J. A., Martínez, J., de la Rubia, T. (2014). Production of the phanerochaete flavido-alba laccase in Aspergillus niger for synthetic dyes decolorization and biotransformation. World Journal of Microbiology and Biotechnology, 30(1), 201-211.

Bingol, D., Tekin, N. \& Alkan, M. (2010). Brilliant yellow dye adsorption onto sepiolite using a full factorial design. Applied Clay Science, 50, 315-321.

Blessing, N. D., Ihuoma, A., Obioma, K. A., Ngozi, N. O. (2018). Citric acid production potential of Aspergillus niger using Chrysophyllum albidum peel. Advances in Bioscience and Biotechnology, 9, 190-203.

Box, G.E.P., Wilson, K.B. (1951). On the experimental attainment of optimum conditions. J. R. Statistical Societies (Series B). 13, 1-45.

Chukwuemeka, I C., Ethel, O.C., Kalu, A.D., Chukwuma, N. (2019). Citric acid production by Aspergillus niger using banana and plantain peels. GSC Biological and Pharmaceutical Sciences, 08(02), 015-021.

Darouneh, E., Alavi, A., Vosoughi, M., Arjmand, M., Sifkordi, A., Rabaji, R. (2009). Citric acid production: surface culture versus submerged culture. African Journal of Microbiology Research, 3(9), 541-545.

del Campo, G., Berregi, I., Caracena, R., Santos, J.I. (2006). Quantitative analysis of malic and citric acids in fruit juices using proton nuclear magnetic resonance spectroscopy. Analytica Chimica Acta, 56, 462468.

Dutta, A., Sahoo, S., Mishra, R. R., Pradhan, B., Das, A., Behera, B.C. (2019). A comparative study of citric acid production from different agro-industrial wastes by Aspergillus niger isolated from mangrove forest soil. Environmental and Experimental Biology, 17, 115-122.

Fawole, O.B., Odunfa, S.A. (2003). Some factors affecting production of pectin enzymes by Aspergillus niger. International Biodeterioration and Biodegradation, 53(4), 223-227.

Hair, J.F.Jr., Anderson, R.E., Tatham, R.L., Black, W.C. (1995). Multivariate Data Analysis ( $3^{\text {rd }}$ ed). New York: Macmillan.

Hesham, A.E., Mostafa, Y.S., AlSharqi, L.E.O. (2020). Optimization of citric acid production by immobilized cells of novel yeast isolates. Mycobiology, 48(2), 122-132.

Imandi, S.B., Bandaru, V.V.R., Somalanka, S.R., Garapati, H.R. (2007). Optimization of medium constituents for the production of citric acid from by product glycerol using Doehlert Experiment Design. Enzyme and Microbial Technology, 40, 1367-1372.

Jalal, A., Rashid, N., Rasool, N., Akhtar, M. (2009). Gene cloning and characterization of a xylanase from a newly isolated Bacillus subtilis strain R5. Journal of Bioscience and Bioengineering, 107, 360-365. 
Jianlong, W. (1998). Improvement of citric acid production by Aspergillus niger with addition of phytate to beet molasses. Bioresource Technology, 65 (3), 243-245.

Kapoor, K., Chaudhary, K., Tauro, P. (1982). Citric acid. In Read, G. (Ed) Prescott and Dunn's Industrial Microbiology, $4^{\text {th }}$ Edition. CBS Publishers Ltd. New Delhi, India. Pp.709-739.

Kareem, S.O., Rahman, R. A. (2013). Utilization of banana peels for citric acid production by Aspergillus niger. Agriculture and Biology. Journal of North America, 4(4), 384-387.

Khairan, K., Makstum, A., Yulvizar, C. (2019). Utilization of banana peel waste for citric acid production by Aspergillus niger. IOP Conference Series: Earth and Environmental Science, 364: 012005, 1-7. DOI: 10.1088/1755-1315/364/1/012005

Khosravi, D.K., Zoghi, A. (2008). Comparison of pre-treatment strategies of sugar cane bagasse: experimental design for citric acid production. Bioresource Technology, 99, 6986-6993.

Kishore, K.A., Reddy, G.V. (2011). Optimization of operating variables in the fermentation of citric acid using response surface methodology. $2^{\text {nd }}$ International Conference on Chemical Engineering and Applications, 23, 108-113.

Kobomoje, O.S., Mohammed, A.O., Omojasola, P.F. (2013). The production of citric acid from shea nut shell (Vitellaria paradoxa) using Aspergillus niger. Advances in Applied Science Research, 4(2), 25-28.

Kubicek, C.P. (1998). The role of sugar uptake and channeling for citric acid accumulation by Aspergillus niger. Food Technology and Biotechnology, 36, 173-175.

Kudzai, C.T., Ajay, K., Ambika, P. (2016). Citric acid production by Aspergillus niger using different substrates. Malaysian Journal of Microbiology, 12(3), 199-204.

Kumari, K.S., Babu, I.S., Rao, G.H. (2008). Process optimization for citric acid production from raw glycerol using response surface methodology. Indian Journal of Biotechnology, 7, 496-501.

Lingappa, K., Naik, C., Vivekbabu, C.S., Reddy, V. (2001). Effect of initial moisture content on the yield of citric acid by Aspergillus niger under solid state fermentation. Asian Journal of Microbiology Biotechnology and Environmental Science,3(4): 365-368.

Max, B., Salgado, J.M., Rodríguez, N., Cortés, S., Converti, A., Domínguez, J. M. (2010). Biotechnological production of citric acid. Brazilian Journal of Microbiology, 41(4), 862-875.

Nadeem, A., Syed, Q., Baig, S., Irfan, H., Nadeem, M. (2010). Enhanced production of citric acid by Aspergillus niger M-101 using lower alcohols. Turkey Journal Biochemistry, 35(1), 7-13.

Navaratnam, P., Arasaratnam, V., Balasubramaniam, K. (1998). Channeling of glucose by methanol for citric acid production from Aspergillus niger. World Journal of Microbiolology and Biotechnology, 14(4), 559-563.

Oladele, K.O., Siew, Q.Y., Zakry, F.A.A., Lan, J.C., Ling, T. C. (2015). Overview of citric acid production from Aspergillus niger. Frontiers in Life Science, 8(3), 271 - 283.

Pandey, A. (1992). Recent process developments in solid state fermentation. Process Biochemistry, 27, 109-117.

Patil, N. G., Patil, V.R. (2014). Production and partial characterization of citric acid by local isolate of Aspergillus niger using sorghum. International Research Journal of Pharmacy, 5(3), 229-231.

Ringle, C.M., Wende, S., Becker, Jan-Michael. (2015). SmartPLS 3. Bönningstedt: SmartPLS. Retrieved from http://www.smartpls.com.

Sawant, O., Mahale, S., Ramchandran, V., Nagaraj, G., Bankar, A. (2018) Fungal citric acid production using waste materials: a mini-review. Journal of Microbiology, Biotechnology and Food Sciences, 8(2), 821-828.

Soccol, C.R., Vandenberghe, L. P. S., Rodrigues, C., Pandey, A. (2006). New perspectives for citric acid Production and application. Food Technology and Biotechnology, 44(2): 141-149.

Thiruvengadam, S., Thangavel, S. (2016). Optimization of citric acid production using Aspergillus niger isolated from the leaf litter soil of Sathuragiri Hills. Universal Journal of Microbiology Research, 4(4), 79-87.

Urak, S., Yeniay, O., Karasu-Yalcin, S. (2014). Optimization of citric acid production from a carrot juice-based medium by Yarrowia lipolytica using response surface methodology. Annals of Microbiology, 65(2), 639-649.
Usami, S., Watanabe, T., Suzuki, H., Nakagawa, K., Kirimura, K. (1998). Citric acid production from cellulose hydrolysate by a 2 Deoxyglucose resistant mutant strain of Aspergillus niger. Bioresource Technology, 66:271-274.

Uzah, G. A., Akani, N. P., Odu, N. N. (2020). Screening of Aspergillus and Candida species with utmost potential to synthesize citric acid. Journal of Advances in Microbiology, 20(4), 10-18.

Varsha, G. S. (2015). Production and optimization of citric acid by Aspergillus niger using molasses and corncob. International Journal of Pharmaceutical Science, 7(5), 152-157.

Varshney, A. S. (2016). Production, comparative and quantitative analysis of citric acid by Aspergillus niger using food waste as a substrate. Journal of Experimental Food Chemistry, 2(4), 1-6.

Yu, D., Shi, Y, Wang, Q, Zhang, X., Zhao, Y. (2017). Application of methanol and sweet potato vine hydrolysate as enhancers of citric acid production by Aspergillus niger. Bioresources and Bioprocessing, 4(35): 1-13 